\title{
Adubação Nitrogenada em Pastagem de Triticale mais Azevém sob Pastejo com Lotação Contínua: Recuperação de Nitrogênio e Eficiência na Produção de Forragem ${ }^{1}$
}

\author{
André Brugnara Soares ${ }^{2}$, João Restle ${ }^{3}$
}

\begin{abstract}
RESUMO - O objetivo do experimento foi avaliar a eficiência da adubação nitrogenada na forma de uréia, em pastagem de triticale mais azevém, submetida a pastejo com lotação contínua. Foram usados quatro níveis de nitrogênio em cobertura: $0,150,300$ e $450 \mathrm{~kg}$ $\mathrm{N} /$ ha, divididos em cinco aplicações. A massa de forragem disponível foi de 1404, 1437, 1619 e $1599 \mathrm{~kg}$ MS/ha, respectivamente. A produção total de forragem foi de $6039,6914,7877$ e $7662 \mathrm{~kg} \mathrm{MS} /$ ha e a produção de nitrogênio, de 191,6; 247,7; 303,2 e 307,2 kg/ha, para os níveis $0,150,300$ e $450 \mathrm{~kg} \mathrm{~N} / \mathrm{ha}$, respectivamente. A eficiência da adubação nitrogenada foi de 5,83; 6,13; e 3,61 kg MS/kg de nitrogênio aplicado e a recuperação de nitrogênio, de 37,39; 37,21 e 25,69\%, para os níveis 150, 300 e $450 \mathrm{~kg}$ N/ha, respectivamente. Na avaliação da concentração de nitrogênio nas camadas do perfil do solo (0-5, 5-10, 10-20 e 20-40 cm de profundidade), em duas datas (20/07 e 20/09), constatou-se aumento no teor de nitrogênio mineral, da primeira para a segunda avaliação, principalmente nas maiores profundidades e nos maiores níveis de nitrogênio, indicando que houve perdas por lixiviação, diminuindo a recuperação e eficiência no uso deste nutriente.
\end{abstract}

Palavras-chave: eficiência, lixiviação, nitrogênio, pastejo, recuperação, uréia

\section{Nitrogen Fertilization on Triticale plus Italian Ryegrass Pasture under Continuous Stocking: Nitrogen Recovery and Forage Production Efficiency}

\begin{abstract}
The objective of this experiment was to evaluate the nitrogen fertilization efficiency using urea, on triticale plus Italian ryegrass pasture, submitted to continuous stocking. Four nitrogen levels were used: $0,150,300$ and $450 \mathrm{~kg}$ of N/ha, divided in five applications. The herbage mass was $1404,1437,1619$ and $1599 \mathrm{~kg}$ of DM/ha. The total herbage production was $6039,6914,7877$ and $7662 \mathrm{~kg}$ of DM/ha and the nitrogen production was 191.6, 247.7,303.2 and $307.2 \mathrm{~kg}$ of N/ha for the $0,150,300$ and $450 \mathrm{~kg}$ of N/ha levels, respectively. The nitrogen fertilization efficiency was 5.83, 6.13 and $3.61 \mathrm{~kg}$ of DM produced/ $\mathrm{kg}$ of nitrogen applied and the nitrogen recovery was $37.39,37.21$ and $25.69 \%$ for the levels of 150,300 and $450 \mathrm{~kg}$ of N/ha, respectively. The nitrogen concentration in different depth of the soil profile (0-5, 5-10,10-20 and 20-40 cm of depth) in two dates (07/20 and 09/20) was evaluated. An increase of the mineral nitrogen content, from the first to the second evaluation, mainly for the deepest layers and for the highest nitrogen levels was observed, indicating that lixiviation losses of nitrogen occured, reducing the nitrogen recovery and his efficiency.
\end{abstract}

Key Words: efficiency, grazing, lixiviation, nitrogen, recovery, urea

\section{Introdução}

A produtividade de uma pastagem de gramíneas depende de vários fatores, como condições climáticas e edáficas e manejo a que são submetidas, principalmente em relação ao nível de nitrogênio, por tratar-se do nutriente mais limitante ao crescimento das plantas (Chapin et al., 1987). A falta deste nutriente às plantas pode afetar a fotossíntese diretamente, por meio de efeitos na síntese e atividade da enzima responsável pela assimilação do $\mathrm{CO}_{2}$ (RUBISCO) (Makino et al., 1984). Alterações deste tipo podem ter significado bastante expressivo em termos práti- cos, podendo-se obter respostas lineares de rendimento de MS até o nível de $300 \mathrm{~kg} \mathrm{~N} /$ ha, em gramíneas sob lotação contínua (Soares, 1999). Por outro lado, o nitrogênio é o insumo de custo mais elevado nas pastagens cultivadas de inverno. Segundo Restle et al. (1999), a adubação nitrogenada (445 kg de uréia/ha) representou $41,77 \%$ da composição dos custos para implantação e uso da pastagem de aveia preta mais azevém. Utilizando a mistura de triticale mais azevém, Soares (1999) cita que a adubação nitrogenada (389 $\mathrm{kg}$ de uréia/ha) representou $39,86 \%$ do custo total da pastagem. Portanto, o estudo da eficiência do uso deste nutriente em pastagem de inverno, sob pastejo,

\footnotetext{
${ }^{1}$ Parte da Dissertação de Mestrado do primeiro autor - UFSM.

${ }^{2}$ Aluno de Doutorado do Departamento de Plantas Forrageiras e Agrometeorologia - UFRGS, RS (Fone: 0xx51-3387-7021. E.mail:jupanqui@zipmail.com.br)

${ }^{3}$ Eng $^{\circ}$-Agr ${ }^{\circ}$, PhD, Prof. Titular do Departamento de Zootecnia - UFSM, pesquisador do CNPq - Campus UFSM, Cep 97105 900 , Santa Maria RS. E.mail: jorestle@ccr.ufsm.br
} 
é de extrema importância, uma vez que se trata do elemento mais exigido pelas plantas, que mostram potencial de resposta, mas também é um nutriente de custo elevado, quando usado na forma de fertilizante químico.

Os aumentos do rendimento de matéria seca, para cada unidade de nutriente disponível, diminuem, à medida que o rendimento se aproxima do potencial máximo de produção da planta (Armitage et al., 1964). Isto ocorre porque as perdas são proporcionais à dose aplicada e, além de diminuir a recuperação e eficiência no uso do nitrogênio, podem trazer problemas de contaminação da água subterrânea pelo excesso de nitrato (Griffith et al., 1997; Guimerà, 1998).

Trabalhando com diferentes fontes de nitrogênio, com doses de 112, 224 e $448 \mathrm{~kg}$ N/ha em Coastal bermuda a campo, Burton \& Jackson (1962) encontraram as seguintes porcentagens médias de nitrogênio recuperado pela pastagem: nitrato de amônio, $81,3 \%$; sulfato de amônio, 80,1\%; amônia anidra, $78,4 \%$; e uréia, $60,2 \%$. Os autores verificaram que a porcentagem de nitrogênio recuperado decresceu com o incremento da quantidade aplicada para as fontes testadas, com exceção da amônia anidra.

Os resultados de pesquisa em relação às perdas do nitrogênio são extremamente variados, principalmente porque o nitrogênio proveniente da uréia é muito suscetível às perdas e, conseqüentemente, muito sensível às condições de manejo de aplicação. Esta suscetibilidade às perdas é a principal diferença entre os principais fertilizantes nitrogenados utilizados no Brasil (uréia e sulfato de amônio); quanto mais cuidados forem tomados para evitar perdas, mais a uréia se equiparará ao sulfato de amônio em relação à eficiência de produção e produção de MS.

Avaliando a lixiviação do nitrato proveniente da uréia, Bauder \& Schneider (1979) usaram colunas de solo franco argiloso e níveis de irrigação: adequada e excessiva. A quantidade de uréia aplicada foi de $135 \mathrm{~kg} \mathrm{~N} / \mathrm{ha}$, em uma ou três aplicações no desenvolvimento do trigo. Os autores concluíram que o total de nitrato lixiviado foi proporcional ao volume de água, ou seja, quanto maior quantidade de água adicionada, maiores as perdas de nitrato por lixiviação.

Os principais fatores que controlam a velocidade e a quantidade de nitrogênio mineral que se perde por lixiviação são textura, estrutura, porosidade, regime pluvial, capacidade de retenção de água e de cátions do solo, presença e tipo de cobertura vegetal e método de aplicação do fertilizante.
Outra importante diferença entre os experimentos que avaliam recuperação e eficiência no uso do nitrogênio em forrageiras é a presença do animal. Em geral, a concentração de nitrogênio nas forrageiras de inverno é superior às necessidades dos animais. Este excedente de nitrogênio retorna à pastagem, contribuindo com as perdas (Ball \& Ryden, 1984; Steenvoorden et al., 1986). Segundo Kemp et al. (1979), aproximadamente $80 \%$ do nitrogênio consumido pelos animais é excretado, principalmente na urina (65-80\%), e a recuperação do nitrogênio urinário e sua conversão em MS é baixa quando a pastagem é bem fertilizada com este nutriente (Deenen \& Middelkoop, 1992), aumentando assim as perdas.

No Brasil, o consumo de nitrogênio é de 1.177.000 t/ano (ANDA, 1995). Por ser o nutriente mais consumido e de custo mais elevado nas condições brasileiras, são necessários estudos que possibilitem seu uso de forma mais eficiente. Devido à sua importância econômica, existem poucas informações científicas de resposta da produção animal e da pastagem frente a níveis de nitrogênio em experimentos com pastejo, bem como o estudo da eficiência no uso do nitrogênio. Entre os trabalhos produzidos sob lotação contínua em pastagem de gramíneas de inverno, destacam-se os de Restle et al. (1993) e Lupatini et al. (1998), que utilizaram níveis crescentes de nitrogênio até $300 \mathrm{~kg} / \mathrm{ha}$, observando respostas lineares tanto na produção de matéria seca como no ganho de peso/ha.

Ainda não existe no nosso meio um embasamento científico a respeito do uso de níveis de nitrogênio em pastagem de triticale mais azevém, sob pastejo com lotação contínua. Portanto, o objetivo do presente experimento foi avaliar aspectos relacionados à adubação nitrogenada, como produção de MS da pastagem, eficiência do uso do nitrogênio, recuperação e perdas por lixiviação deste elemento em pastagem de triticale e azevém submetida à lotação contínua.

\section{Material e Métodos}

O experimento foi conduzido no período de abril a novembro de 1997, na área experimental do Departamento de Zootecnia da Universidade Federal de Santa Maria, situada na Depressão Central do Rio Grande do Sul, numa altitude de 95 m, latitude 29 $43^{\prime}$ sul e longitude $53^{\circ} 42^{\prime}$ oeste. O clima da região é Cfa (subtropical úmido), conforme classificação de Köppen, com precipitação média anual de 1769 mm, 
temperatura média anual de $19,2^{\circ} \mathrm{C}$, com média mínima de $9,3^{\circ} \mathrm{C}$ em junho e média máxima de $24,7^{\circ} \mathrm{C}$ em janeiro, insolação de 2212 horas anuais e umidade relativa do ar de $82 \%$ (Moreno, 1961). No entanto, o período experimental foi afetado pelo fenômeno "el niño", no qual houve precipitação superior e insolação inferior à normal (Tabela 1).

O solo da área experimental pertence à unidade de mapeamento São Pedro, classificado como Podzólico Vermelho-Amarelo, apresentando um relevo levemente ondulado, com solo de textura superficial arenosa, naturalmente ácidos, pobres em matéria orgânica e nutrientes, com baixa CTC e saturação por bases (Oliveira et al., 1992). A análise de solo, feita por ocasião do início do experimento, mostrou os seguintes valores: $\mathrm{pH}\left(\mathrm{H}_{2} \mathrm{O}\right)=5,1 ; \mathrm{P}=11,7 \mathrm{mg} / \mathrm{L}$; $\mathrm{K}=43,2 \mathrm{mg} / \mathrm{L} ; \mathrm{MO}=2,5 \% ; \mathrm{Al}=0,7 \mathrm{cmolc} / 1 ;$ $\mathrm{Ca}=5,2 \mathrm{cmolc} / \mathrm{L} ; \mathrm{Mg}=5,2 \mathrm{cmolc} / \mathrm{L} ; \mathrm{CTC}=11,3 \mathrm{cmolc} / \mathrm{L}$.
Os tratamentos constaram de níveis de nitrogênio em cobertura, na forma de uréia, a saber: $0,150,300$ e $450 \mathrm{~kg} \mathrm{~N} / \mathrm{ha}$. A área do experimento constou de 10 ha divididos em dez piquetes, em que foram usados oito piquetes (dois para cada tratamento) e dois piquetes para a permanência dos animais reguladores. A área média dos piquetes foi de 1 ha.

O preparo do solo foi realizado do dia 20 ao dia 24 de março de 1997, por intermédio de uma aração, com arado gradeador, a uma profundidade aproximada de $12 \mathrm{~cm}$, seguida de uma gradagem leve com grade niveladora. A adubação de base foi realizada após a aração, com o auxílio de uma semeadeira-adubadeira centrífuga, utilizando as recomendações da CFSRS/SC (1995), para fósforo e potássio, sendo que foi usada a mesma adubação de base para todos os tratamentos. Foram utilizados $100 \mathrm{~kg} / \mathrm{ha}$ de cloreto de potássio e $100 \mathrm{~kg} / \mathrm{ha}$ de superfosfato triplo, correspondendo a

Tabela 1 - Observações meteorológicas ocorridas e normais, referentes ao período experimental (abril a novembro de 1997) Table 1 - Occurred and normal meteorological observations, during the experimental period (April to November, 1997)

\begin{tabular}{|c|c|c|c|c|c|}
\hline $\begin{array}{l}\text { Mês } \\
\text { Month }\end{array}$ & $\begin{array}{c}\text { Temp. } \\
\text { máxima }\left({ }^{\circ} \mathrm{C}\right) \\
\text { Max. temp. }\end{array}$ & $\begin{array}{c}\text { Temp. } \\
\text { mínima }\left({ }^{\circ} \mathrm{C}\right) \\
\text { Min. temp }\end{array}$ & $\begin{array}{c}\text { Precipitação } \\
\text { Rainfall } \\
\text { (mm) }\end{array}$ & $\begin{array}{c}\text { Insolação } \\
\text { Sunlight } \\
\text { (h) }\end{array}$ & $\begin{array}{c}\text { Evaporação } 1 \\
\text { (mm/dia) } \\
\text { Evaporation } 1 \\
\text { (mm/day) }\end{array}$ \\
\hline Abril & 26 & 13,8 & 679 & 207,3 & 3,12 \\
\hline \multicolumn{6}{|l|}{ April } \\
\hline Normal & 25,6 & 14,5 & 157,0 & 172,0 & \\
\hline Maio & 22,9 & 11,4 & 112,2 & 204,1 & 2,61 \\
\hline \multicolumn{6}{|l|}{ May } \\
\hline Normal & 22,2 & 11,7 & 191,0 & 155,0 & \\
\hline Junho & 18,6 & 9,9 & 187,6 & 113,8 & 1,66 \\
\hline \multicolumn{6}{|l|}{ June } \\
\hline Normal & 19,6 & 9,7 & 163,0 & 133,0 & \\
\hline Julho & 20,1 & 11,9 & 110,0 & 138,0 & 2,10 \\
\hline \multicolumn{6}{|l|}{ July } \\
\hline Normal & 19,4 & 9,3 & 135,0 & 147,0 & \\
\hline Agosto & 22,9 & 12,5 & 160,3 & 162,0 & 2,99 \\
\hline \multicolumn{6}{|l|}{ August } \\
\hline Normal & 19,4 & 9,8 & 145,0 & 156,0 & \\
\hline Setembro & 22,6 & 12,5 & 58,0 & 165,1 & 3,24 \\
\hline \multicolumn{6}{|l|}{ September } \\
\hline Normal & 22,2 & 11,6 & 163,0 & 157,0 & \\
\hline Outubro & 23,3 & 15,4 & 476,8 & 45,4 & 2,31 \\
\hline \multicolumn{6}{|l|}{ October } \\
\hline Normal & 24,2 & 12,8 & 152,0 & 196,0 & \\
\hline Novembro & 25,9 & 17,6 & 193,1 & 158,1 & 2,21 \\
\hline \multicolumn{6}{|l|}{ November } \\
\hline Normal & 26,9 & 14,9 & 121,0 & 218,0 & \\
\hline Média ocorrida & 22,26 & 12,77 & 206,67 & 142,64 & 2,49 \\
\hline \multicolumn{6}{|l|}{ Ocurred mean } \\
\hline $\begin{array}{l}\text { Média normal } \\
\text { Normal mean }\end{array}$ & 21,82 & 11,31 & 155,06 & 162,99 & \\
\hline
\end{tabular}

${ }^{1}$ Medida feita no tanque "classe A".

${ }^{1}$ Measure made in "classe A" tank. 
uma quantidade de $40 \mathrm{~kg} / \mathrm{ha}$ de $\mathrm{P}_{2} \mathrm{O}_{5}$ e $60 \mathrm{~kg} / \mathrm{ha}$ de $\mathrm{K}_{2} \mathrm{O}$.

As espécies foram semeadas individualmente, devido à diferença no peso específico das sementes, com o objetivo de uniformizar a distribuição das mesmas.

Depois da gradagem leve, foi semeado o triticale cv. IAPAR 23, com semeadeira-centrífuga, em uma densidade de $185 \mathrm{~kg} / \mathrm{ha}$, a lanço, no dia 21 de abril. A incorporação das sementes foi feita com nova gradagem leve, porém com "pouca trava" (grade niveladora fechada). Logo após a incorporação das sementes do triticale, seguindo a mesma metodologia, foi feita a semeadura do azevém e, logo após, foi passado rolo compactador em toda a área. A densidade de semeadura foi de $35 \mathrm{~kg} / \mathrm{ha}$.

A quantidade total de nitrogênio foi dividida em cinco aplicações, sendo realizadas nas seguintes datas: 23/05, 20/06, 10/07, 05/08 e 10/09/1997. A primeira aplicação foi feita durante o afilhamento da pastagem, 32 dias após a semeadura, antes da entrada dos animais, sendo que nesta aplicação foram usados $25 \%$ da dose total; as demais foram doses iguais de 18,75\% da quantidade total. A quantidade maior de nitrogênio na primeira aplicação foi realizada porque não havia sido usado nitrogênio na adubação de base. A fonte de nitrogênio usada foi a uréia, sendo tomados, na medida do possível, os devidos cuidados para minimizar as perdas de nitrogênio, como observar as condições de umidade do solo e a temperatura ambiente, na ocasião da aplicação dos tratamentos.

A massa de forragem de MS das pastagens foi avaliada a cada 28 dias aproximadamente, retirando-se dez amostras $\left(0,25 \mathrm{~m}^{2} /\right.$ amostra $)$ por piquete, as quais foram cortadas acima do mantilho, com tesoura de esquila. A primeira avaliação da massa de forragem foi realizada no dia 12/06/97, apresentando massa de forragem média de 1608, 1457, 1991 e $1779 \mathrm{~kg} \mathrm{MS/ha,} \mathrm{para}$ os níveis de $0,150,300$ e $450 \mathrm{~kg} \mathrm{~N} / \mathrm{ha}$, respectivamente. Este foi o momento da entrada dos animais na pastagem, 52 dias após a semeadura. Os animais usados, tanto os testes como os reguladores, foram bezerras com idade média inicial de sete meses e peso médio inicial de $154 \mathrm{~kg}$ e final de $271 \mathrm{~kg}$, pertencentes aos grupos genéticos Charolês, $3 / 4$ Charolês $1 / 4$ Nelore e $3 / 4$ Nelore $1 / 4$ Charolês. A lotação usada foi dependente da disponibilidade de MS, mantendo-se massa de forragem próxima a $1600 \mathrm{~kg}$ MS/ha. Nas amostras da massa de forragem, foi determinado o teor de nitrogênio total pelo método micro Kjeldahl (AOAC, 1984), as quais foram realizadas no Laboratório de Nutrição Animal da EMBRAPA -
CPPSUL, Bagé - RS.

Também foi avaliada a taxa de acúmulo de MS, com o uso de quatro gaiolas de exclusão ao pastejo por piquete, sendo que esta foi estimada, em cada período, por intermédio da equação descrita por Campbell (1966). A produção total de forragem foi obtida somando as produções de forragem de cada período.

O cálculo da eficiência no uso do nitrogênio foi realizado calculando-se a diferença entre a produção total de forragem de cada tratamento em relação ao tratamento testemunha (admitindo-se que a contribuição do nitrogênio do solo foi semelhante entre os tratamentos) e dividido pela quantidade de nitrogênio aplicada, sendo expressa, portanto, em $\mathrm{kg}$ de MS produzida/kg de nitrogênio aplicado (Lupatini et al., 1998).

O total de nitrogênio recuperado (absorvido) pela pastagem foi calculado multiplicando-se a produção de MS pelo teor médio de nitrogênio (\% MS) na massa de forragem, descontando-se a produção de nitrogênio do testemunha.

A recuperação do nitrogênio foi calculada da seguinte forma:

$$
R N(\%)=\frac{(N C T-N S T)}{N N} * 100
$$

em que $\mathrm{RN}(\%)$ corresponde à recuperação do nitrogênio; $\mathrm{NCT}$, ao nitrogênio total absorvido com o tratamento $(\mathrm{kg} / \mathrm{ha})$; NST, ao nitrogênio total absorvido sem aplicação da adubação (tratamento testemunha) $(\mathrm{kg} / \mathrm{ha})$; e $\mathrm{NN}$, ao nível de nitrogênio usado $(\mathrm{kg} / \mathrm{ha})$.

$\mathrm{O}$ nitrogênio contido nas raízes e no mantilho não foi determinado; dessa forma, quando se fala em recuperação de nitrogênio, que é o percentual de nitrogênio absorvido do total que foi aplicado, considera-se somente o nitrogênio contido na parte aérea da planta, provavelmente a recuperação do nitrogênio seria maior se fosse contabilizado todo nitrogênio absorvido pela planta (parte aérea, raíz e mantilho).

$O$ valor de porcentagem de nitrogênio na massa de forragem do primeiro período foi aplicado no modelo de diluição de nitrogênio de Lemaire \& Chartier (1992), para avaliar o grau de nutrição nitrogenada da planta, ou seja, este modelo fornece uma porcentagem de nitrogênio ideal para determinado nível de produção de MS. Se os valores reais ficam acima dos fornecidos pelo modelo, é sinal de que ocorreu um consumo de luxo de nitrogênio. Se isto ocorre, é porque a planta não está metabolizando todo nitrogênio absorvido e convertendo-o em acúmulo de MS. 
Nos dias 20/07 e 20/09, foram feitas coletas de solo para determinação do nitrogênio mineral no perfil do solo; ambas avaliações foram feitas dez dias depois de uma adubação nitrogenada. Para a estimativa de lixiviação do nitrogênio no perfil do solo, foi medida a concentração de amônia $\left(\mathrm{NH}^{3+}\right)$ e nitrato $\left(\mathrm{NO}^{2-}\right)$ em diferentes profundidades: 0 a 5,5 a 10, 10 a 20 e 20 a $40 \mathrm{~cm}$. Os três primeiros estratos foram coletados com o uso de uma pá de corte, já na profundidade de 20 a $40 \mathrm{~cm}$ foi usado um trado do tipo holandês. Foram coletadas amostras em 15 pontos/ unidade experimental (piquete). O nitrogênio mineral consta da soma do nitrogênio na forma amoniacal e na forma nítrica. Para determinação do conteúdo de nitrogênio no solo, foi usado o método descrito por Tedesco et al. (1995).

O delineamento experimental utilizado foi o inteiramente casualizado, com duas repetições (piquetes). Os dados foram submetidos à análise de variância pelo GLM (SAS, 1990) e análise de regressão, testando-se os modelos linear, quadrático e cúbico, a 5\% de significância. A escolha do modelo ao qual os dados mais se ajustavam baseou-se no nível de significância e nos coeficientes de determinação e variação.

\section{Resultados e Discussão}

Conforme pode ser observado na Tabela 2, a produção de forragem foi de 6039, 6914, 7877 e $7662 \mathrm{~kg} \mathrm{MS} / \mathrm{ha}$, correspondendo a uma taxa de acúmulo de 32,$44 ; 37,26 ; 42,48 ;$ e 41,32 kg MS/ha/ dia, respectivamente, para os níveis de $0,150,300$ e $450 \mathrm{~kg} \mathrm{~N} /$ ha. Nota-se que houve comportamento quadrático com os níveis de nitrogênio e o nível que promoveu o máximo crescimento foi de $387,5 \mathrm{~kg} \mathrm{~N} / \mathrm{ha}$.
Os dados de taxa de acúmulo foram inferiores aos obtidos por Roso (1998) o qual, com a mesma mistura forrageira e $220 \mathrm{~kg} \mathrm{~N} / \mathrm{ha}$, encontrou valor médio de taxa de acúmulo de $48,12 \mathrm{~kg} \mathrm{MS} / \mathrm{ha} / \mathrm{dia}$. No entanto, este autor não computou a taxa de acúmulo ocorrida no período de afilhamento, antes da entrada dos animais. Lupatini et al. (1998), trabalhando com aveia preta mais azevém na mesma área experimental, usaram níveis de 0,150 e $300 \mathrm{~kg} \mathrm{~N} / \mathrm{ha}$ e obtiveram valores de taxa de acúmulo de 37, 82 e $96 \mathrm{~kg} \mathrm{MS} / \mathrm{ha} /$ dia. Observa-se que, no presente trabalho, a diferença de produção de MS de 0 para $150 \mathrm{~kg} \mathrm{~N} / \mathrm{ha}$ foi de apenas $15 \%$; enquanto que no trabalho dos referidos autores foi de $122 \%$ e, quando o nível de nitrogênio aumentou de 150 para $300 \mathrm{~kg} / \mathrm{ha}$, a diferença foi de 17,1\% (Lupatini et al., 1998); no presente experimento, esta diferença foi de $14 \%$. Esta relativa alta produtividade do tratamento testemunha pode ser explicada pelo histórico da área onde foi desenvolvido o presente experimento. A mesma vem recebendo níveis relativamente altos de nitrogênio desde 1989 e boa adubação de base a cada cultivo, que pelo efeito residual de outras adubações pode ter diminuído o efeito dos tratamentos neste trabalho.

O solo do presente experimento apresenta uma fertilidade muito boa para um podzólico com teor médio de matéria orgânica de $2,5 \%$, o que também é um bom teor para este tipo de solo. Esta matéria orgânica pode ter contribuído para a menor diferença entre os tratamentos, uma vez que parte da matéria orgânica é mineralizada pela microbiota do solo, liberando formas disponíveis de nitrogênio para as plantas (Camargo et al., 1999).

As condições climáticas que ocorreram durante o andamento do trabalho (Tabela 1) também limitaram a resposta ao $\mathrm{N}$, pois ocorreu relativo excesso de

Tabela 2 - Recuperação de nitrogênio e total de nitrogênio recuperado na pastagem de triticale mais azevém submetida a níveis de nitrogênio

Table 2 - Nitrogen recovery and total nitrogen recovered on triticale plus ryegrass pasture submitted to nitrogen levels

\begin{tabular}{|c|c|c|c|}
\hline $\begin{array}{l}\text { Tratamento } \\
\text { Treatment }\end{array}$ & $\begin{array}{l}\text { Produção total } \\
{\text { (kg MS } / \mathrm{ha})^{1}} \\
\text { Total production } \\
(\mathrm{kg} \mathrm{DM} / \mathrm{ha})^{1}\end{array}$ & $\begin{array}{c}\text { Total de } \mathrm{N} \text { recuperado } \\
(\mathrm{kg} / \mathrm{ha}) \\
\text { Total } \mathrm{N} \text { recovered } \\
(\mathrm{kg} / \mathrm{ha})\end{array}$ & $\begin{array}{c}\text { Recuperação do } \mathrm{N} \\
(\%) \\
N \text { recovery }\end{array}$ \\
\hline 0 & 6039 & 191,60 & - \\
\hline 150 & 6914 & 247,69 & 37,39 \\
\hline 300 & 7877 & 303,23 & 37,21 \\
\hline 450 & 7662 & 307,21 & 25,69 \\
\hline
\end{tabular}

1 Produção total de MS (Total DM production) $=5975,62+9,34 \mathrm{~N}-0,012 \mathrm{~N}^{2}\left(\mathrm{P}<0,021, \mathrm{R}^{2}=0,4608\right)$. 
umidade no solo, devido ao fenômeno meteorológico "el niño", fato que pode ter dificultado o desenvolvimento das plantas pela falta de oxigênio. O excesso de umidade do solo favoreceu perdas de nitrogênio por lixiviação e, possivelmente, por desnitrificação, podendo ser um dos motivos que limitou a diferença entre os tratamentos. A insolação também foi de $12,48 \%$ inferior à normal.

De acordo com o modelo de diluição de nitrogênio de Lemaire \& Chartier (1992) (Tabela 3), observa-se, em todos os níveis de nitrogênio, relativo excesso deste nutriente, pois a concentração de nitrogênio real foi de 3,$47 ; 3,91 ; 3,98$; e 4,16 pontos percentuais superior em relação ao teor de nitrogênio fornecido pelo modelo, respectivamente, para os níveis de 0,150 , 300 e $450 \mathrm{~kg} \mathrm{~N} / \mathrm{ha}$. Isto significa que as plantas não responderam, em termos de acúmulo de MS, de forma satisfatória a todo nitrogênio que foi aplicado.

Este modelo foi desenvolvido sem a presença do animal; dessa forma, os dados colocados no modelo foram as produções de forragem do primeiro período, em que os animais ainda não haviam entrado na pastagem, e o teor de nitrogênio da massa de forragem na primeira avaliação, que foi feita um dia antes da entrada dos animais na área.

A eficiência de utilização do nitrogênio ou, segundo alguns autores (Mazzanti et al., 1997), resposta aparente do crescimento de forragem, depende de vários fatores, entre eles a fonte de nitrogênio, as condições do solo e climáticas, grau de fracionamento e dose aplicada, potencial de resposta da planta, presença do animal, entre outros (Mello, 1987; Lupatini et al., 1998).

Tabela 3 - Teor de nitrogênio (\% na MS), real e do modelo, da produção de MS do primeiro período e eficiência de utilização do nitrogênio ( $\mathrm{kg}$ de MS produzida/ $\mathrm{kg}$ de nitrogênio aplicado) da pastagem de triticale mais azevém, submetida a níveis de nitrogênio

Table 3 - Nitrogen content (\% DM), real and from the model, of the DM production of the first period and utilization efficiency of the nitrogen ( $\mathrm{kg}$ of DM produced $/ \mathrm{kg}$ of nitrogen applied) of the Triticale plus Ryegrass pasture, submitted to nitrogen levels

Trat. \%nitrogênio real \% nitrogênio modelo ${ }^{1}$ Eficiência

$\begin{array}{lll}\text { Treat. } \% \text { real } N & \% \text { nitrogen } \text { model }^{1} \quad \text { Efficiency }\end{array}$

\begin{tabular}{llll}
\hline 0 & 3,86 & 0,39 & \\
150 & 4,31 & 0,40 & 5,83
\end{tabular}

$\begin{array}{llll}150 & 4,31 & 0,40 & 5,83 \\ 300 & 4,34 & 0,36 & 6,13\end{array}$

$\begin{array}{llll}450 & 4,54 & 0,38 & 3,61\end{array}$

${ }^{1}$ Nitrogênio $=4,8$ (produção MS) ${ }^{-0.34}$.

${ }^{1}$ Nitrogen $=4.8(\text { DM production })^{-0.34}$.
Em resumo, os fatores que influem na taxa de acúmulo da planta e na recuperação de nitrogênio também influenciam a eficiência de utilização deste nutriente.

Os dados de eficiência de utilização do nitrogênio foram de 5,83; 6,13; e 3,61 para 150,300 e $450 \mathrm{~kg} \mathrm{~N} /$ ha, respectivamente (Tabela 3 ). Houve redução na eficiência de utilização somente a partir dos $300 \mathrm{~kg} \mathrm{~N} / \mathrm{ha}$, o que discorda de Lupatini et al. (1998), que encontraram diminuição da eficiência, a partir do primeiro nível de nitrogênio ( $150 \mathrm{~kg} / \mathrm{ha})$, e de Mazzanti et al. (1997), que obtiveram relação linear inversa entre crescimento de forragem e níveis de nitrogênio, sendo que os valores variaram de 8 a $52 \mathrm{~kg}$ de $\mathrm{MS} / \mathrm{kg}$ de nitrogênio aplicado entre 0 e $250 \mathrm{~kg} \mathrm{~N} / \mathrm{ha}$. Este comportamento de queda de eficiência somente a partir do nível de $300 \mathrm{~kg} \mathrm{~N} /$ ha discorda da maioria dos trabalhos que avaliou este parâmetro (Whitehead, 1995; Mazzanti et al., 1997).

$\mathrm{O}$ nível de $300 \mathrm{~kg} \mathrm{~N} /$ ha propiciou às plantas a produção de $5 \%$ a mais de matéria seca a cada $\mathrm{kg}$ de nitrogênio aplicado, em relação aos $150 \mathrm{~kg} \mathrm{~N} / \mathrm{ha}$, enquanto o nível de $450 \mathrm{~kg} \mathrm{~N} /$ ha produziu $38 \%$ a menos por kg de nitrogênio.

O teor médio de nitrogênio, na massa de forragem, de junho a novembro foi de 3,$17 ; 3,58 ; 3,85$; e $4,01 \%$, correspondendo a um teor de PB de 19,83; 22,$39 ; 24,06$; e $25,06 \%$, respectivamente para os níveis de $0,150,300$ e $450 \mathrm{~kg} \mathrm{~N} / \mathrm{ha}$. Verificou-se aumento linear no teor de $\mathrm{PB}$ com os níveis de nitrogênio ( $\left.P B=20,19+0,0119 N ; P<0,0001, R^{2}=0,9045\right)$. Segundo Mazzanti et al. (1997), é possível duplicar o teor de nitrogênio na planta, ao aumentar o nível de adubação nitrogenada de 0 para $250 \mathrm{~kg} \mathrm{~N} / \mathrm{ha}$. Nesse caso, mesmo aumentando a adubação nitrogenada de 0 para $450 \mathrm{~kg} \mathrm{~N} / \mathrm{ha}$, elevou-se apenas $26,49 \%$ o teor de nitrogênio da massa de forragem. A diferença é que, no trabalho do referido autor, o tratamento testemunha apresentou $1,69 \%$ de nitrogênio, enquanto no presente experimento este tratamento apresentou 3,17\%.

O total de nitrogênio absorvido pela parte aérea da pastagem foide 191,60;247,69; 303,23; e 307,21 kg N/ha, todos valores maiores que os obtidos por Alvim et al. (1987), adubando aveia branca com $400 \mathrm{~kg} \mathrm{~N} / \mathrm{ha}$.

A recuperação ou, para alguns autores (Lira et al., 1996), porcentagem de utilização foi praticamente a mesma para os níveis 150 e $300 \mathrm{~kg} \mathrm{~N} / \mathrm{ha}(37 \%)$ (Tabela 2). Provavelmente, as perdas tenham ocorrido de forma proporcionalmente similar. Já em $450 \mathrm{~kg} \mathrm{~N} /$ ha houve redução na recuperação, sendo que esta foi de apenas $25,7 \%$, sendo as perdas mais 
elevadas. A similaridade na recuperação do nitrogênio entre 150 e $300 \mathrm{~kg} \mathrm{~N} /$ ha foi atribuída à relativa alta produção de nitrogênio do tratamento testemunha (191,6 kg N/ha), é a mesma situação da eficiência de utilização do nitrogênio visto anteriormente. Os valores obtidos discordam dos de Alvim et al. (1987), que, trabalhando com aveia branca, obtiveram recuperações de 56, 41, 32 e 30\% para as doses 100, 200, 300 e $400 \mathrm{~kg} \mathrm{~N} / \mathrm{ha}$, sendo que as produções de $\mathrm{MS} / \mathrm{kg}$ nitrogênio foram decrescentes.

Com o aumento de 300 para $450 \mathrm{~kg} \mathrm{~N} / \mathrm{ha}$, houve limitação do ambiente (solo e clima), para responder de forma eficiente, e incemento das perdas de nitrogênio. Outra hipótese para explicar esta queda de eficiência nos maiores níveis é que o pH em água tem relação linear negativa com níveis de nitrogênio (pHágua $=5,80-0,0057 \mathrm{~N}, \mathrm{R}^{2}=0,61$, Barak et al., 1997) e talvez nos maiores níveis de nitrogênio tenha ocorrido uma acidificação que possa ter limitado a absorção dos nutrientes, como nitrogênio, fósforo, cálcio e potássio, ou talvez causado aumento na disponibilidade de alumínio que causa efeito tóxico (Malavolta, 1980).

Na primeira avaliação do teor de nitrogênio mineral no perfil do solo (20/07), foi verificada maior concentração desse elemento mineral na profundidade de 0 a $5 \mathrm{~cm}$, independentemente do tratamento (Tabela 4), diminuindo de forma linear com o aumento da profundidade. Os valores variaram de 3,81 a $0,87 \mathrm{mg}$ de $\mathrm{N} / \mathrm{kg}$ de solo para as profundidades de 0 a 5 e de 20 a $40 \mathrm{~cm}$, respectivamente. Pelo maior teor de matéria orgânica na superfície, produto da decomposição de massa de forragens vegetais e presença de nutrientes provindos da fertilização química, é natural que se encontre maior concentração de nitrogênio na camada de 0 a $5 \mathrm{~cm}$. Comparando-se as médias das profundidades para cada tratamento, não houve diferença significativa entre eles.

Na segunda avaliação (20/09), os teores de nitrogênio mineral foram de 9,94 e $8,65 \mathrm{mg}$ de N/kg de solo, para as profundidades de 0 a 5 e de 20 a $40 \mathrm{~cm}$, respectivamente, sendo que não houve diferença significativa. Observou-se aumento do nitrogênio, da primeira para a segunda avaliação, em todas as camadas avaliadas, no entanto, este incremento foi percentualmente maior nas camadas mais profundas. Como visto anteriormente, na primeira avaliação, o teor de nitrogênio mineral diminuiu de forma linear, com o aumento da profundidade, e na segunda avaliação não houve diferença entre as profundidades, o que indica perdas de nitrogênio por lixiviação. Quando comparadas as médias das profundidades para cada nível de nitrogênio, houve efeito quadrático, em que a maior concentração $(25,45 \mathrm{mg} / \mathrm{kg}$ de solo) foi encontrada no maior nível de nitrogênio. Segundo Bauder \&

Tabela 4 - Teor de nitrogênio mineral (mg de N/kg de solo) em diferentes profundidades do solo, em duas avaliações, na pastagem de triticale mais azevém submetida a níveis de nitrogênio

Table 4 - Mineral nitrogen content ( $\mathrm{mg}$ of $\mathrm{N} / \mathrm{kg}$ of soil) in different depth of the soil profile, at two evaluation dates, on triticale plus ryegrass pasture, submitted to nitrogen levels

\begin{tabular}{|c|c|c|c|c|c|c|}
\hline \multirow[b]{2}{*}{$\begin{array}{l}\text { Avaliação } \\
\text { Evaluation }\end{array}$} & \multirow[b]{2}{*}{$\begin{array}{c}\text { Profundidade }(\mathrm{cm}) \\
\text { Depth }(\mathrm{cm})\end{array}$} & \multicolumn{4}{|c|}{$\begin{array}{c}\text { Tratamento } \\
\text { Treatment }\end{array}$} & \multirow[b]{2}{*}{$\begin{array}{l}\text { Média } \\
\text { Mean }\end{array}$} \\
\hline & & 0 & 150 & 300 & 450 & \\
\hline$\overline{20 / 07}$ & $0-5$ & 2,39 & 3,28 & 5,66 & 3,90 & $3,81^{1}$ \\
\hline $07 / 20$ & $5-10$ & 2,11 & 2,18 & 2,31 & 2,60 & 2,30 \\
\hline & $10-20$ & 0,52 & 0,60 & 1,63 & 1,37 & 1,03 \\
\hline & $20-40$ & 1,15 & 0,43 & 0,60 & 1,31 & 0,87 \\
\hline $\begin{array}{l}\text { Média } \\
\text { Mean }\end{array}$ & & $1,54^{3}$ & 1,63 & 2,55 & 2,30 & \\
\hline $20 / 09$ & $0-5$ & 5,43 & 2,53 & 9,52 & 22,30 & $9,94^{3}$ \\
\hline & $5-10$ & 4,93 & 1,13 & 3,50 & 28,34 & 9,48 \\
\hline & $10-20$ & 2,17 & 1,16 & 5,43 & 24,59 & 8,34 \\
\hline & $20-40$ & 0,87 & 2,52 & 4,65 & 26,56 & 8,65 \\
\hline $\begin{array}{l}\text { Média } \\
\text { Mean }\end{array}$ & & $3,35^{2}$ & 1,84 & 5,87 & 25,45 & \\
\hline
\end{tabular}

${ }_{1}^{1}$ Nitrogênio mineral (mineral $\left.N\right)=4,52-1,0071 P\left(P<0,0001, R^{2}=0,5954\right)$.

${ }^{2}$ Nitrogênio mineral $($ mineral $N)=3,86-0,059 N+0,00023 N^{2}\left(P<0,0001, R^{2}=0,7247\right)$.

$3 \mathrm{P}>0,05$. 
Schneider (1979), as perdas por lixiviação são proporcionais ao volume de água que passa pelo perfil do solo e, no mês de agosto, houve fortes precipitações que ocasionaram as perdas (Tabela 1).

$\mathrm{O}$ aumento dos teores de nitrogênio (média das diferentes camadas), em todos os tratamentos, exceto o testemunha, pode ser explicado, além da mineralização da matéria orgânica, pelo próprio nitrogênio da fertilização, pois a segunda avaliação foi feita depois da quantidade total de nitrogênio ser aplicada e a primeira, após a aplicação de $62,5 \%$ da quantidade total. $\mathrm{O}$ aumento foi percentualmente maior no nível de $450 \mathrm{~kg} \mathrm{~N} /$ ha pela menor recuperação do nitrogênio neste tratamento.

\section{Conclusões}

A adubação nitrogenada proporcionou aumento de forma quadrática na produção de matéria seca da pastagem estudada, sendo que o nível de maior produção foi de $379 \mathrm{~kg} \mathrm{~N} /$ ha. Houve também aumento no teor de nitrogênio e proteína bruta da pastagem, mas sem proporcionalidade com o aumento nos níveis de adubação, pois a recuperação e a eficiência do nitrogênio diminuem com o aumento da quantidade aplicada à pastagem, sendo que a partir de $300 \mathrm{~kg} \mathrm{~N} / \mathrm{ha}$ aumentam as perdas de nitrogênio por lixiviação.

\section{Literatura Citada}

ALVIM, M.J.; MARTINS, C.E.; CÓSER, A.C. et al. Efeito da fertilização nitrogenada sobre a produção de matéria seca e teor de proteína bruta da aveia (Avena sativa L.) nas condições da zona da mata de Minas Gerais. Revista Brasileira de Zootecnia, v.16, n.4, p.394-401, 1987.

ANDA. Anuário Estatístico Setor de Fertilizantes. São Paulo: Associação Nacional para Difusão de Adubos e Corretivos Agrícolas: São Paulo, 1995. 151p.

ASSOCIATION OF OFFICIAL ANALYTICAL CHEMISTS AOAC. Official methods of analysis. 14.ed. washington, D.C., 1984. 1141p.

ARMITAGE, E.R.; TEMPLEMAN, W.G. Response of grassland to nitrogenous fertilizer in the west of England. Journal of the British Grassland Society, n.19, p.291-297, 1964.

BALL, P.R.; RYDEN, J.C. Nitrogen relashionships in intensively managed temperate grassland. Plant and Soil, v.79, p.23-33, 1984.

BARAK, P.; JOBE, B.O.; KRUEGER, A.R. et al. Effects of long-term soil acidification due to nitrogen fertilizer inputs in Wisconsin. Plant and Soil, n.197, p.61-69, 1997.

BAUDER, J.W.; SCHNEIDER, R.P. Nitrate -nitrogen leaching following urea fertilizations and leaching. Journal Soil Science Society American, v.43, p.744-747, 1979.
BURTON, G.W.; JACKSON, J.E. Effect of rate frequency of applying six nitrogen sources on coastal bermudagrass. Agronomy Journal, v.54, n.1, p.40-43, 1962.

CAMARGO, F.A.O.; GIANELO, C.; VIDOR, C. Nitrogen fractions in the microbiota biomass in soils of southern Brazil. Revista Brasileira de Ciência do Solo, v.23, n.1, p.181-185, 1999.

CAMPBELL, A.G. Grazed pastures parameters; I. Pasture dry matter production and availability in a stocking rate and grazing management experiment with dairy cows. Journal of Agriculture Science, v.67, p.211-216, 1966.

CHAPIN, F.S.; BLOOM, A.J.; FIELD, C.B. et al. Plant response to multiple environmental factors. BioScience, v.37, p.49-57, 1987.

COMISSÃO DE FERTILIDADE DO SOLO - CFSRS/SC. Recomendações de adubação e calagem para os estados do Rio Grande do Sul e Santa Catarina. 3.ed. Passo Fundo: SBCS - Núcleo Regional Sul, 1995. 233p.

DEENEN, P.J.A.G.; MIDDELKOOP, N. Effect of cattle dung and urine on nitrogen uptake and yield of perenial ryegrass. Journal of Agricultural Science, v.40, p.469-482, 1992.

GRIFFITH, S.M.; OWEN, J.S.; HORWATH, W.R. et al. Nitrogen movement and water quality at a poorly-drained agricultural and riparian site in the Pacific Northwest. Soil Science Plant Nutrition, v.43, p.1025-1030, 1997.

GUIMERÀ, J. Anomalously high nitrate concentrations in ground water. Ground water, v.36, n.2, p.275-282, 1998.

KEMP, A.; HEMKES, O.J.; VAN STEENBERGEN, J. et al. The crude protein production of grassland and utilization by milking cows. Journal of Agricultural Science, v.27, p.36-47, 1979.

LEMAIRE, G.; CHARTIER, M. Relationships between growth dynamics and nitrogen uptake for individual sorghum plants growing at different plant densities. In.: LEMAIRE, G. (Ed.) Diagnosis of the nitrogen status in crops. França: INRA Station décophysiologie des Plantes Fourragères. 1992. p.3-43.

LIRA, M.A.; FARIAS, I.; FERNANDES, A.P.M. et al. Efeito da adubação nitrogenada e fosfatada no rendimento do capimelefante (Pennisetum purpureum, Schum.). Pesquisa Agropecuária Brasileira, v.31, n.1, p.19-26, 1996.

LUPATINI, G.C.; RESTLE, J.; CERETTA, M. et al. Avaliação da mistura de aveia preta e azevém sob pastejo submetida a níveis de nitrogênio. I - Produção e qualidade de forragem. Pesquisa Agropecuária Brasileira, v.33, n.11, p.19391943, 1998.

MAKINO, A.; MAE, T.; OHIRA, K. Relation between nitrogen and ribulose 1,5-biphosphate carboxylasse in rice leaves from emergence through senescence. Plant Cell Physical, v.25, p.429-37, 1984.

MALAVOLTA, E. Os elementos minerais. In: MALAVOLTA, E. (Ed.) Elementos de nutrição mineral de plantas. São Paulo: Agronômica Ceres, 1980. p.104-216.

MAZZANTI, A.; MARINO, M.A.; LATTANZI, F. et al. 1997. Efecto de la fertilización nitrogenada sobre el crecimiento y la calidad del forraje de Avena y Raigrás anual en el sudeste Bonariense, Uruguai: INTA, 1997 (Boletim técnico - INTA, n.143).

MELLO, F.A.F. Uréia fertilizante. Campinas: Fundação Cargill, 1987. 192p.

MORENO, J.A. Clima do Rio Grande do Sul. Porto Alegre: Secretaria da Agricultura, 1961. 41p.

OLIVEIRA, J.B.; JACOMINE, P.K.T; CAMARGO, M.N. Classes gerais de solos do Brasil. Guia auxiliar para seu reconhecimento. 2.ed. Jaboticabal: FUNEP, 1992. 201p. 
RESTLE, J.; LUPATINI, G.C.; VALENTE, A.V. et al. Avaliação da mistura de aveia preta (Avena strigosa) e azevém (Lolium multiflorum) sob pastejo submetida a níveis de nitrogênio. IProdução animal. In: REUNIÃO ANUAL SOCIEDADE BRASILEIRA DE ZOOTECNIA, 30., 1993, Rio de Janeiro. Anais... Rio de Janeiro: Sociedade Brasileira de Zootecnia, 1993. p.71.

RESTlE, J.; ROSO, C.; SOARES, A.B. Produção animal e retorno econômico em misturas de gramíneas anuais de estação fria. Revista Brasileira de Zootecnia, v.28, n.2, p.235243, 1999.

ROSO, C. Produção animal em misturas de gramíneas anuais de estação fria. Santa Maria: Universidade Federal de Santa Maria, 1996. 104p. Dissertação (Mestrado em Zootecnia) - Universidade Federal de Santa Maria, 1998.

SAS INSTITUTE. SAS Language reference. Version 6, Cary: 1990. $1042 p$

SOARES, A.B. Produção animal em pastagem de triticale (Xtriticosecale) mais azevém (Lolium multiflorum) submetida a níveis de adubação nitrogenada. Santa Maria: Universidade Federal de Santa Maria, 1999. 188p. Dissertação (Mestrado em Zootecnia) - Universidade Federal de Santa Maria, 1999.
STEENVOORDEN, J.H.A.M.; FONCK, H.; OOSTEROM, H.P. 1986. Losses of nitrogen from intensive grassland systems by leaching and surface run-off. In.: VAN DER MEER, H.G.; RYDEN, J.C.; ENNIK, G.C. (Eds.) Nitrogen fluxes in intensive grassland systems, Dordrecht: Martinus Nijhoff, 1996. p.85-97.

TEDESCO, M.J.; GIANELLO, C.; BISSANI, C.A. et al. Análise de solo, plantas e outros materiais. Porto Alegre: Universidade Federal do Rio Grande do Sul, 1995. 174p.

WHITEHEAD, D.C. Grassland nitrogen. Wallingford: CAB International, 1995. 397p.

Recebido em: 04/05/00

Aceito em: 13/09/01 